\title{
Ginseng berry aqueous extract prevents scopolamine-induced memory impairment in mice
}

\author{
JIN RYUL HU ${ }^{1}$, YOON SEOK CHUN ${ }^{2}$, JONG KYU KIM $^{2}$, IL JE CHO $^{1}$ and SAE KWANG KU ${ }^{1}$ \\ ${ }^{1}$ Research Center for Herbal Convergence on Liver Disease, College of Korean Medicine, \\ Daegu Haany University, Gyeongsan, Gyeongsangbuk-do 38610; ${ }^{2}$ Central Research Center, \\ Aribio Co., Ltd., Pyeongtaek, Gyeonggi-do 17749, Republic of Korea
}

Received May 28, 2019; Accepted September 9, 2019

DOI: $10.3892 /$ etm.2019.8090

\begin{abstract}
Ginseng berry exhibits a diverse range of pharmacological activities. The present study aimed to examine the neuroprotective effects of ginseng berry aqueous extract (GBE) against oxidative stress and to assess the impact of GBE on memory impairment in mice. In HT-22 cells, GBE pretreatment significantly inhibited glutamate- and hydrogen peroxide-mediated cytotoxicity in a concentration-dependent manner, while treatment with up to $100 \mu \mathrm{g} / \mathrm{ml} \mathrm{GBE}$ alone did not change cell viability. In a murine model of scopolamine (SCP)-induced memory impairment, results from the passive avoidance test and the Morris water maze test indicated that GBE administration for 4 weeks prolonged step-through latency time and shortened escape latency time, suggesting that GBE can attenuate deficits in long-term memory induced by SCP. Additionally, GBE prevented SCP-induced reductions in acetylcholine by decreasing acetylcholinesterase activity and upregulating choline acetyltransferase mRNA levels in the hippocampus. GBE mitigated SCP-mediated mRNA
\end{abstract}

Correspondence to: Dr Il Je Cho or Dr Sae Kwang Ku, Research Center for Herbal Convergence on Liver Disease, College of Korean Medicine, Daegu Haany University, Haneuidaero 1, Gyeongsan, Gyeongsangbuk-do 38610, Republic of Korea

E-mail: gucci200@hanmail.net

E-mail:skek023@dhu.ac.kr

Abbreviations: ACh, acetylcholine; AChE, acetylcholine esterase $\mathrm{AD}$, Alzheimer's disease; BDNF, brain derived neurotropic factor; CaMK, $\mathrm{Ca}^{2+} /$ calmodulin-dependent protein kinase; CAT, catalase; ChAT, choline acetyltransferase; CREB, cAMP response element binding protein; ERK, extracellular signal-regulated kinase; GBE, ginseng berry extract; $\mathrm{GSH}$, glutathione; $\mathrm{H}_{2} \mathrm{O}_{2}$, hydrogen peroxide; HPLC, high-performance liquid chromatography; Nrf2, nuclear factor-E2 related factor 2; PI3K, phosphoinositide 3-kinase; SCP, scopolamine; SD, standard deviation; SOD, superoxide dismutase; TrkB, tropomyosin receptor kinase B

Key words: acetylcholine, antioxidant, brain-derived neurotrophic factor, ginseng berry aqueous extract, scopolamine-induced memory impairment decreases in brain-derived neurotrophic factor levels and its associated signaling molecules. Furthermore, GBE administration significantly suppressed malondialdehyde production and increased glutathione levels, catalase activity and superoxide dismutase activity in SCP-induced memory impaired mice. Therefore, the results of the current study indicated that ginseng berry may be a potential candidate for treating or preventing memory deficits that are associated with neurodegenerative disorders.

\section{Introduction}

Alzheimer's disease (AD) is a progressive neurodegenerative disorder that accounts for $60-70 \%$ of patients with dementia (1). While the neuropathological mechanisms of AD remain mostly unknown, they are associated with the accumulation of neurofibrillary tangles and senile plaques that accelerate oxidative stress and decrease cholinergic activity in the brain, which in turn impair memory and cognitive function $(2,3)$. Thus, restoration of cholinergic function in the brain has been suggested to be a standard strategy for delaying the progression of the disease $(3,4)$. Several acetylcholinesterase (AChE) inhibitors have been approved to manage the symptoms of mild AD and are associated with various adverse effects, including nausea, diarrhea, anorexia, vomiting, and hepatic toxicity $(3,5)$. Moreover, no medication has been approved to treat patients with memory deficits. Therefore, traditional herbs may be a valuable resource for treating memory impairment with fewer side effects.

In East Asia, including Korea, root of ginseng (Panax ginseng Meyer) has been prescribed for centuries to tonify ' $q i$ '. It is also used to treat wide range of diseases. Although the bioactive compounds found in this root are also distributed in other parts of ginseng (i.e., berry, stem, leaf, and flower), the berry has often been regarded as a 'useless by-product' and discarded during the process of ginseng root production. However, accumulated evidence suggests that ginseng berry contains high levels of ginsenosides $(6,7)$ and has more potent pharmacological activities than the root $(6,8,9)$. In particular, it has been reported that the ginseng berry has beneficial effects in decreasing blood glucose (9), sensitizing insulin signaling (10), inhibiting adipogenesis (11), reducing blood coagulation (12), enhancing blood circula- 
tion $(6,8)$, ameliorating cisplatin-induced nephrotoxicity (13) and acetaminophen-induced hepatotoxicity (14), and inhibiting dextran sodium sulfate-induced colitis (15). Despite its potential beneficial effects on diverse diseases, the effects of ginseng berry against amnesia remain poorly understood.

Thus, the present study aimed to examine the in vitro neuroprotective effects of ginseng berry aqueous extract (GBE) against oxidative stress and to explore the in vivo anti-amnesic effects of GBE in a murine model of scopolamine (SCP)-induced memory impairment. Tacrine (9-amino-1,2,3,4-tetrahydroacridine hydrochloride) is a prototypic cholinesterase inhibitor that increases cholinergic transmission at synapses (3). Tacrine has been shown to improve cognitive function in experimental animal models of AD $(16,17)$. To evaluate the therapeutic effects of GBE, tacrine was used as a positive reference drug. Furthermore, the effects of GBE on the cholinergic nervous system, mRNA expression of memory-related genes, and antioxidant activities were further examined to understand its role in memory impairment.

\section{Materials and methods}

Quantification of ginsenoside Re. GBE were prepared and supplied from Aribio Co., Ltd., as previously reported (12). Ginsenoside Re was purchased from ChemFaces (Wuhan, China). Ginsenoside Re concentration in GBE was quantified using high-performance liquid chromatography (HPLC) (Agilent 1100, Agilent Technologies) equipped with reversed phase column (Capcell Pak C18 UG120, 4.6x250 mm, $5 \mu \mathrm{m}$; Shiseido) and diode array detector system (Agilent Technologies). GBE was dissolved in $60 \%$ of methanol, and ginsenoside Re in $100 \%$ of methanol. GBE and ginsenoside Re were eluted using 20-30\% acetonitrile gradient solution containing $0.01 \%$ of phosphoric acid. Ginsenoside Re was detected at the wavelength of $203 \mathrm{~nm}$. Ginsenoside Re in GBE was quantified according to peak area and retention time.

Cell viability assay. HT-22 cells, a murine normal hippocampal neuronal cell line, were obtained from Millipore and maintained at $37^{\circ} \mathrm{C}$ with $5 \% \mathrm{CO}_{2}$. After HT-22 cells $\left(1 \times 10^{4}\right.$ cells/well) were grown for $24 \mathrm{~h}$, the cells were treated with GBE (0.01-100 $\mu \mathrm{g} / \mathrm{ml})$ for $72 \mathrm{~h}$ to examine the effect of GBE on the viability of HT-22 cells. In another experiments, GBE-pretreated HT-22 cells $(0.01-100 \mu \mathrm{g} / \mathrm{ml}, 0.5 \mathrm{~h})$ were subsequently exposed to $5 \mathrm{mM}$ of glutamate or $500 \mu \mathrm{M}$ of hydrogen peroxide $\left(\mathrm{H}_{2} \mathrm{O}_{2}\right)$ for $12 \mathrm{~h}$. Cell viability was measured at wavelength of $450 \mathrm{~nm}$ using EZ-Cytox cell viability assay kit (Daeil Labservice) and automated microplate reader (VersaMax $^{\mathrm{TM}}$; Molecular Devices). The cell viability was calculated as relative to the untreated control cells.

Animal husbandry and treatment. C57BL/6NCrljOri mice ( $\mathrm{n}=120$; male, 18-21 g, 6 weeks old) were supplied from Orient Bio, Inc., maintained with a supply of filtered pathogen-free air, and provided with standard rodent chow (Purinafeed) and water ad libitum at standard condition (temperature, $20-25^{\circ} \mathrm{C}$; light/dark cycle, $12 / 12 \mathrm{~h}$; relative humidity, $40-45 \%)$. After 1 week of acclimatization, mice were divided into 6 groups ( $\mathrm{n}=20 /$ group); vehicle, $\mathrm{SCP}, \mathrm{SCP}+$ tacrine $10 \mathrm{mg} / \mathrm{kg}, \mathrm{SCP}+\mathrm{GBE} 400 \mathrm{mg} / \mathrm{kg}, \mathrm{SCP}+\mathrm{GBE} 200 \mathrm{mg} / \mathrm{kg}$, and SCP + GBE $100 \mathrm{mg} / \mathrm{kg}$. GBE or tacrine dissolving in distilled water was administered orally once a day for 28 days. To induce memory impairment, $1 \mathrm{mg} / \mathrm{kg}$ of SCP dissolving in sterilized saline was intraperitoneally injected three times $1 \mathrm{~h}$ after GBE (or tacrine) administration on days 6, 13 and 27. Instead of GBE and SCP, vehicle group was given an equal volume of distilled water and saline. And SCP group administered distilled water to induce same stresses.

Measurement of body weight. To reduce the differences from feeding, all mice were fasted for $12 \mathrm{~h}$ (water was not) at initiation of first GBE (or tacrine) administration. Body weight was measured on days $-1,0,1,13,20,27$ and 28 using an automatic electronic balance (XB320M; Precisa Instrument).

Passive Avoidance Test. The step-through passive avoidance test $(n=10 /$ group) was conducted, as previously described $(16,18)$. After the last SCP injection, each mouse was placed in the light/noise compartment $30 \mathrm{~min}$ for training mice. Light and noise was applied until the mouse escaped into the neighboring grid floor compartment. An electric shock $(3.0 \mathrm{~mA})$ for $3 \mathrm{sec}$ was applied to the grid floor. A retention test was performed $24 \mathrm{~h}$ after training test using the same condition, and the moving time from the light/noise compartment to the grid floor was recorded as a step-through latency time.

Morris water maze test. The Morris water maze test ( $n=10 /$ group) was carried out using separated animals from the passive avoidance test, as previously reported (19). For training, each mouse was placed in circular pool (diameter, $100 \mathrm{~cm}$; depth, $27 \mathrm{~cm}$; temperature, $22^{\circ} \mathrm{C}$ ) $30 \mathrm{~min}$ after the last SCP injection, and began to find the submerged escape platform (diameter, $10 \mathrm{~cm}$ ) in one of the pool quadrants. When the mouse was successfully placed on the platform, it was allowed to remain on the platform for $10 \mathrm{sec}$. However, if the mouse was failed to find the platform within $150 \mathrm{sec}$, the mouse was placed on the platform for $10 \mathrm{sec}$. A retention test was performed $24 \mathrm{~h}$ after training test, and the escape latency time from the water to the escape platform was recorded using a video tracking system (Smart junior).

Isolation of total RNA and RT-PCR. After the passive avoidance test, the mouse was anesthetized under inhalation anesthesia with 2-3\% of isoflurane (Hana Pharm. Co.), euthanized by cervical dislocation, and the hippocampus ( $n=10 /$ group) was collected. Total RNA was isolated using Trizol reagent (Invitrogen), and then reacted with recombinant DNase I (Ambion) to remove contaminated DNA. cDNA was synthesized using oligo-dT ${ }_{16}$ primer and High-Capacity cDNA Reverse Transcription Kit (Applied Biosystems). RT-PCR was carried out using an ABI Step One Plus Sequence Detection System (Applied Biosystems). Gene specific primer pairs were used as followed: Choline acetyltransferase (ChAT) forward 5'-CTTGGATGGTCCAGGCAC-3', backward 5'-GTCATA CCAACGATTCGCTCC-3'; brain-derived neurotrophic factor (BDNF) forward 5'-GACAAGGCAACTTGGCCTAC-3 ', backward 5'-CTGTCACACACGCTCAGCTC-3'; phosphoinositide 3-kinase (PI3K) forward 5'-TCCAAATACCAG CAGGATCA-3', backward 5'-ATGCTTCGATAGCCGTTC TT-3'; Akt forward 5'-TACTCATTCCAGACCCACGA-3', 
backward 5'-GAGGTTCTCCAGCTTCAGGT-3'; extracellular signal-regulated kinase 1 (ERK1) forward 5'-TGGCTTTCT GACGGAGTATG-3', backward 5'-GGTCCAGGTAGTGCT TGC-3'; ERK2 forward 5'-CCTCAAGCCTTCCAACCTC-3', backward 5'-GCCCACAGACCAAATATCAATG-3'; cAMP response element binding protein (CREB) forward 5'-TAC CCAGGGAGGAGCAATAC-3', backward 5'-GAGGCAGCT TGAACAACA AC-3'; $\mathrm{Ca}^{2+} / \mathrm{cal}^{2}$ modulin-dependent protein kinase (CaMK) IV forward 5'-AAATCAGCCTGGTCCTTG AG-3', backward 5'-GAAGCATTTGCGGTGCACGATG-3'; $\beta$-actin forward 5'-GCTGAGAGGGAAATCGTGCGT-3', backward 5'-TCTGGTTTGAGGTCACGATG-3'. Expression level of $\beta$-actin mRNA was used as endogenous control, and the relative expression level of specific gene was calculated by $2^{-\Delta \Delta \mathrm{Cq}}(20)$.

Quantification of acetylcholine (ACh) and measurement of AChE activity. The hippocampus ( $\mathrm{n}=10 /$ group) was homogenized in ice-cold $0.01 \mathrm{M}$ Tris- $\mathrm{HCl}(\mathrm{pH}$ 7.4) using bead beater (Taco ${ }^{\mathrm{TM}}$ Prep; GeneResearch Biotechnology Corp.) and ultrasonic cell disruptor (KS-750; Madell Technology Corp.), and then centrifuged at $12,000 \mathrm{x}$ g for $15 \mathrm{~min}$. ACh concentration and AChE activity in the hippocampal homogenates were measured using an Amplex Red ACh/AChE assay kit (Invitrogen), according to manufacturer's instruction. Fluorescence intensities at $560 \mathrm{~nm}$ (excitation wavelength) and $590 \mathrm{~nm}$ (emission wavelength) were detected using an automated microplate reader (Infinite 200 Pro; Tecan).

Measurement of antioxidant activities in the cerebral cortex. After mouse that had performed the Morris water maze test was euthanized by cervical dislocation under inhalation anesthesia (2-3\% of isoflurane), the cerebral cortex ( $n=10 /$ group) was collected, homogenized with a buffer consisting of $10 \mathrm{mM}$ sucrose, $10 \mathrm{mM}$ Tris- $\mathrm{HCl}$ (pH 7.4), and 0.1 M ethylenediaminetetraacetic acid, and then clarified by centrifugation. Protein concentration of tissue homogenates was determined using bovine serum albumin as a standard protein. Lipid peroxidation was measured at $525 \mathrm{~nm}$ of wavelength by quantifying concentration of malondialdehyde using a thiobarbituric acid, and was expressed as malondialdehyde (ng) per tissue (g). After homogenates were precipitated by $25 \%$ of trichloroacetic acid, reduced glutathione (GSH) contents in resulting supernatants were determined at $412 \mathrm{~nm}$ of wavelength using a 2-nitrobenzoic acid, and were expressed as $\mathrm{nM} / \mathrm{mg}$ protein. Decomposition of $\mathrm{H}_{2} \mathrm{O}_{2}$ by tissue homogenates was measured at $240 \mathrm{~nm}$. One unit of catalase (CAT) activity was defined as the amount of enzyme required to degrade $1 \mathrm{nM}$ of $\mathrm{H}_{2} \mathrm{O}_{2}$ for $1 \mathrm{~min}$. After homogenates were reacted with nitroblue tetrazolium to form formazan, absorbance at $560 \mathrm{~nm}$ was measured for determining superoxide dismutase (SOD) activity. One unit of SOD activity was defined as the amount of enzyme that can reduce initial absorbance of nitroblue tetrazolium by $50 \%$ for $1 \mathrm{~min}$. Specific activity was expressed as U/mg protein.

Statistical analysis. All numerical values are expressed as the mean \pm standard deviation (SD) ( $\mathrm{n}=6$ for in vitro assay; $\mathrm{n}=10$ or 20 for in vivo assay). One-way ANOVA was used to assess the significance among experimental groups, followed by Tukey's honest significance difference or Dunnett's T3 as post hoc analysis. $\mathrm{P}$ values less than 0.05 were considered as statistical differences of significance.

\section{Results}

GBE prevents oxidative stress-mediated cytotoxicity in HT-22 cells. Ginsenoside Re is one of the most abundant ginsenosides found in the ginseng berry $(12,21)$. Before investigating the beneficial effects of GBE, we quantified the concentration of ginsenoside Re in GBE using HPLC under optimized conditions. HPLC analysis indicated that the GBE used in this study contained $29.13 \pm 0.15 \mathrm{mg} / \mathrm{g}$ of ginsenoside Re (Fig. 1A). Next, we examined whether GBE exerted cytotoxic effects against HT-22 cells. Using a cell viability assay, no statistical differences were found when HT-22 cells were exposed to up to $100 \mu \mathrm{g} / \mathrm{ml}$ of GBE for $72 \mathrm{~h}$ (Fig. 1B). To explore the cytoprotective effects of GBE, GBE-pretreated HT-22 cells were continuously exposed to $5 \mathrm{mM}$ of glutamate or $500 \mu \mathrm{M}$ of $\mathrm{H}_{2} \mathrm{O}_{2}$, representative oxidative stressors of neuronal cells, for $12 \mathrm{~h}$. As expected, treatment with glutamate or $\mathrm{H}_{2} \mathrm{O}_{2}$ alone significantly decreased the cell viability of HT-22 cells ( $\mathrm{P}<0.01$; Fig. $1 \mathrm{C}$ and D). However, pretreatment with GBE tended to increase cell viability in a concentration-dependent manner. Compared with glutamate-treated cells, a significant difference in cell viability was observed in cells pretreated with $0.1-100 \mu \mathrm{g} / \mathrm{ml}$ of GBE $(\mathrm{P}<0.05,0.01 \mu \mathrm{g} / \mathrm{ml}$ GBE; P<0.01, 1-100 $\mu \mathrm{g} / \mathrm{ml}$ GBE; Fig. 1C). Relative cell viability after treatment with glutamate, glutamate $+0.01 \mu \mathrm{g} / \mathrm{ml} \mathrm{GBE}$, glutamate $+0.1 \mu \mathrm{g} / \mathrm{ml} \mathrm{GBE}$, glutamate $+1 \mu \mathrm{g} / \mathrm{ml} \mathrm{GBE}$, glutamate $+10 \mu \mathrm{g} / \mathrm{ml} \mathrm{GBE}$, and glutamate $+100 \mu \mathrm{g} / \mathrm{ml} \mathrm{GBE}$ was $43.0 \pm 4.4,43.2 \pm 8.0,55.0 \pm 5.5,62.0 \pm 6.3,66.5 \pm 5.7$ and $69.5 \pm 7.2 \%$ of control cells, respectively. In addition, $1-100 \mu \mathrm{g} / \mathrm{ml}$ of GBE significantly reduced $\mathrm{H}_{2} \mathrm{O}_{2}$-mediated cytotoxicity in $\mathrm{HT}$-22 cells ( $\mathrm{P}<0.01$; Fig. 1D). Relative cell viability after treatment with $\mathrm{H}_{2} \mathrm{O}_{2}$, $\mathrm{H}_{2} \mathrm{O}_{2}+0.01 \mu \mathrm{g} / \mathrm{ml} \mathrm{GBE}, \mathrm{H}_{2} \mathrm{O}_{2}+0.1 \mu \mathrm{g} / \mathrm{ml} \mathrm{GBE}, \mathrm{H}_{2} \mathrm{O}_{2}+1 \mu \mathrm{g} / \mathrm{ml}$ GBE, $\mathrm{H}_{2} \mathrm{O}_{2}+10 \mu \mathrm{g} / \mathrm{ml} \mathrm{GBE}$, and $\mathrm{H}_{2} \mathrm{O}_{2}+100 \mu \mathrm{g} / \mathrm{ml} \mathrm{GBE}$ was $42.3 \pm 3.4,42.5 \pm 1.1,52.7 \pm 8.4,60.3 \pm 8.0,63.7 \pm 7.6$ and $65.0 \pm 4.9 \%$ of control cells, respectively. These results suggest that GBE can protect neuronal cells from oxidative stress in vitro.

GBE mitigates SCP-induced memory impairment in mice. The hippocampus is involved in cognitive function including memory, learning, and emotion. To expand the findings that GBE can protect hippocampal neuronal cells from oxidative stress in vitro, we tested its effects in vivo using a SCP-induced memory impairment murine model. C57BL/6NCrljOri mice (6 weeks old, male) were orally administered one of three dosages of GBE $(100-400 \mathrm{mg} / \mathrm{kg})$ or tacrine $(10 \mathrm{mg} / \mathrm{kg}$; positive control) once per day for 28 days (i.e., initial GBE administration on day 0). To induce memory impairment, SCP was intraperitoneally injected three times, $1 \mathrm{~h}$ after GBE administration on days 6, 13, and 27 (Fig. 2A). All mice experienced a decrease in body weight on day 0 due to an overnight fasting period of $12 \mathrm{~h}$, and body weight gradually increased during the 28-days of the experimental period. There were no significant differences in body weight among the experimental groups (Fig. 2B). Two behavior tests were conducted to investigate the neuroprotective effects associated with the hippocampus. In the retention trial, the passive avoidance test indicated that SCP decreased the step-through latency time compared with the vehicle-treated control group 
A

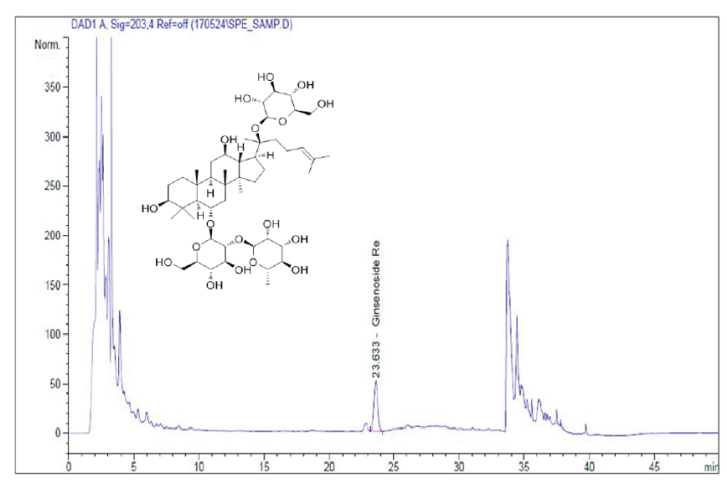

C

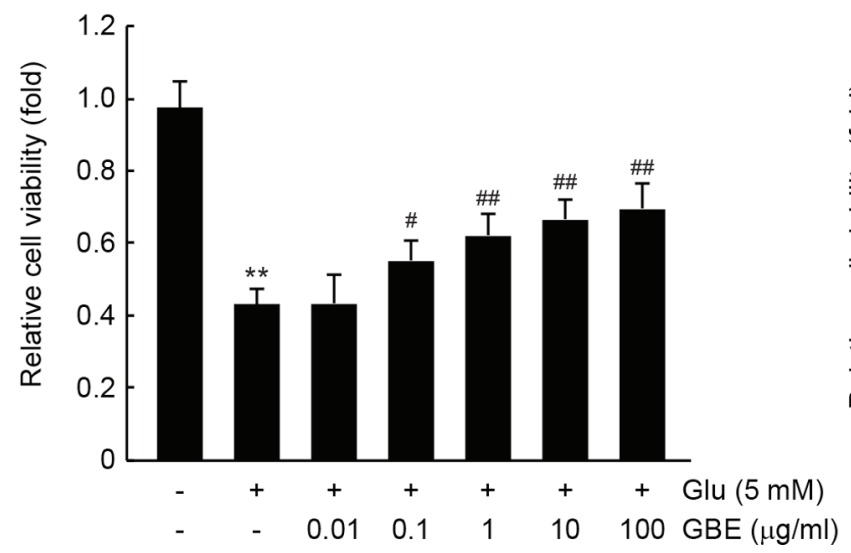

B

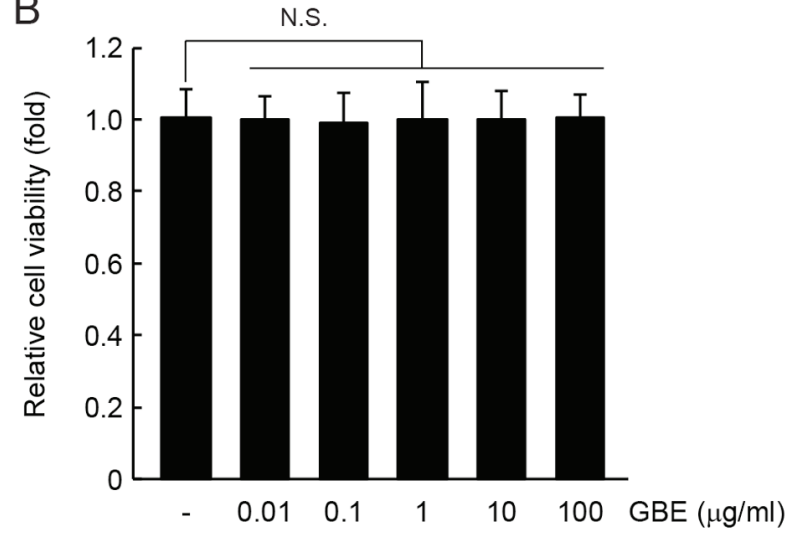

D

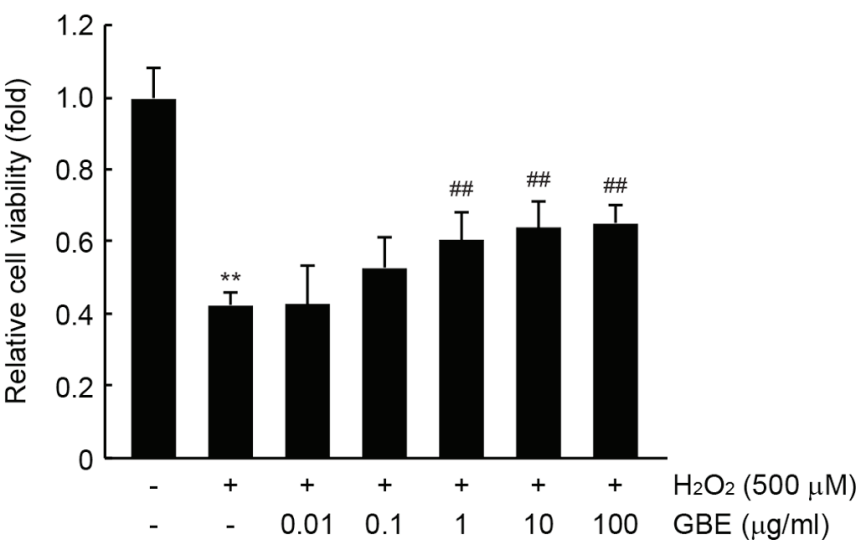

Figure 1. GBE protects HT-22 cells from oxidative stress. (A) Ginsenoside Re in GBE was quantified using a high-performance liquid chromatography. (B) Cell viability assay. HT-22 cells were treated with GBE $(0.01-100 \mu \mathrm{g} / \mathrm{ml})$ for $72 \mathrm{~h}$. Relative cell viability was determined using the EZ-Cytox cell viability assay kit. (C, D) After HT-22 cells were pretreated with GBE (0.01-100 $\mu \mathrm{g} / \mathrm{ml})$ for $0.5 \mathrm{~h}$, the cells were further exposed to (C) $5 \mathrm{mM}$ glutamate or (D) $500 \mu \mathrm{M}$ $\mathrm{H}_{2} \mathrm{O}_{2}$ for $12 \mathrm{~h}$. All values are expressed as the mean $\pm \mathrm{SD}$ of 6 independent experiments. ${ }^{* *} \mathrm{P}<0.01$ vs. vehicle-treated control; ${ }^{\# \#} \mathrm{P}<0.01$, ${ }^{\#} \mathrm{P}<0.05$ vs. glutamate- or $\mathrm{H}_{2} \mathrm{O}_{2}$-treated cells. GBE, ginseng berry aqueous extract; Glu, glutamate; N.S., not significant; SD, standard deviation.

$(\mathrm{P}<0.01)$. However, administration of all three dosages of GBE or tacrine significantly prevented the decrease in step-through latency time by SCP $(\mathrm{P}<0.01)$. Specifically, the increase in step-through latency time in mice treated with $400 \mathrm{mg} / \mathrm{kg}$ of GBE was significantly higher than in mice treated with tacrine $(\mathrm{P}<0.05$; Fig. $2 \mathrm{C})$. Similarly, SCP injection resulted in increased latency time in the Morris water maze $(\mathrm{P}<0.01)$, and treatment with the three dosages of GBE significantly decreased the escape time $(\mathrm{P}<0.01)$. There were no statistical differences of latency time between mice administered GBE vs. tacrine (Fig. 2D). Collectively, these results suggest that GBE can improve cognitive function in mice with SCP-induced memory impairment.

GBE enhances cholinergic nervous system functioning in the hippocampus. To investigate whether GBE prevents memory impairment by enhancing cholinergic signaling in the hippocampus, we measured mRNA levels of ChAT, which produces ACh from acetyl-CoA and choline. As expected, SCP injection significantly decreased ChAT mRNA levels $(\mathrm{P}<0.01)$. However, all three dosages of GBE or tacrine administration prevented this reduction in hippocampal ChAT mRNA $(\mathrm{P}<0.01)$. Specifically, ChAT mRNA levels in mice treated with $400 \mathrm{mg} / \mathrm{kg}$ of GBE were higher than those in mice treated with $10 \mathrm{mg} / \mathrm{kg}$ of tacrine $(\mathrm{P}<0.05$; Fig. 3, left). In addition, GBE administration significantly alleviated the reduction of Ach by SCP in the hippocampus $(\mathrm{P}<0.01$; Fig. 3 , middle). Moreover, the increase in hippocampal AChE activity after SCP injection was significantly decreased following GBE administration with all three dosages $(\mathrm{P}<0.01$; Fig. 3, right). ACh concentration and AChE activity after treatment with the three dosages of GBE were comparable to those after treatment with tacrine.

GBE increases $m R N A$ levels of memory-related genes in the hippocampus. BDNF is a representative neurotrophic factor associated with formation and storage of memory that activates CREB through transducing cellular signaling involving PI3K, Akt, ERK1, ERK2, and CaMK VI (22-24). To examine the effects of GBE on mRNA levels of memory-related genes, RT-PCR analysis was conducted using hippocampal RNAs. SCP significantly decreased mRNA levels of BDNF, PI3K, Akt, ERK1, ERK2, CaMK VI, and CREB (P<0.01; Table I). Administration of 200 and $400 \mathrm{mg} / \mathrm{kg}$ of GBE prevented the reduction of mRNA levels of all genes related to memory in the hippocampus (PI3K in $200 \mathrm{mg} / \mathrm{kg} \mathrm{GBE}: \mathrm{P}<0.05 ; \mathrm{P}<0.01$ for the others), while treatment with $100 \mathrm{mg} / \mathrm{kg}$ of GBE only 
A

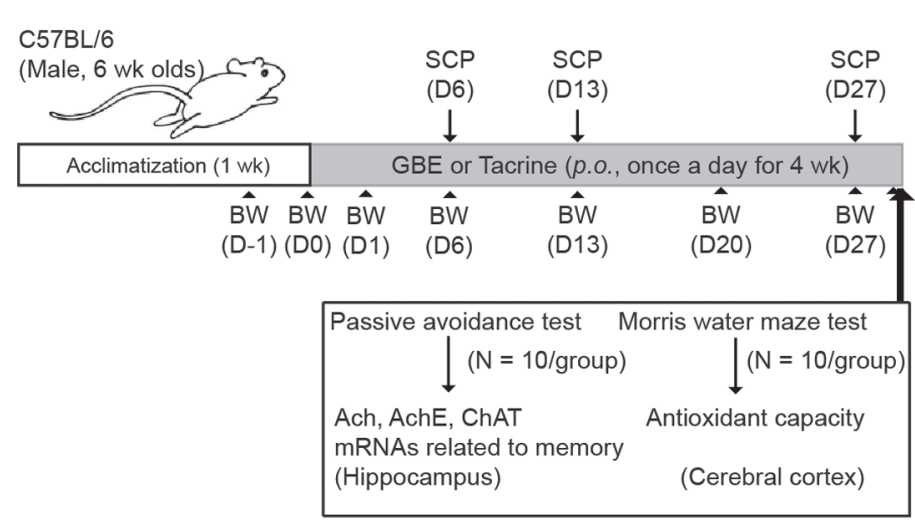

B

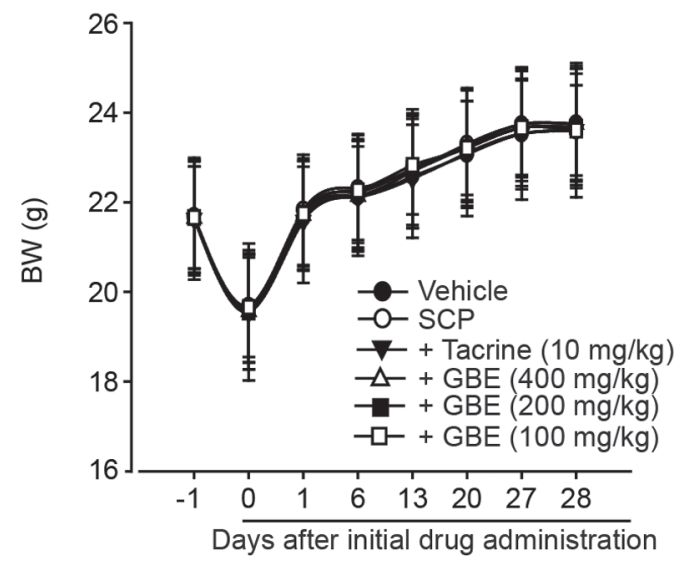

C

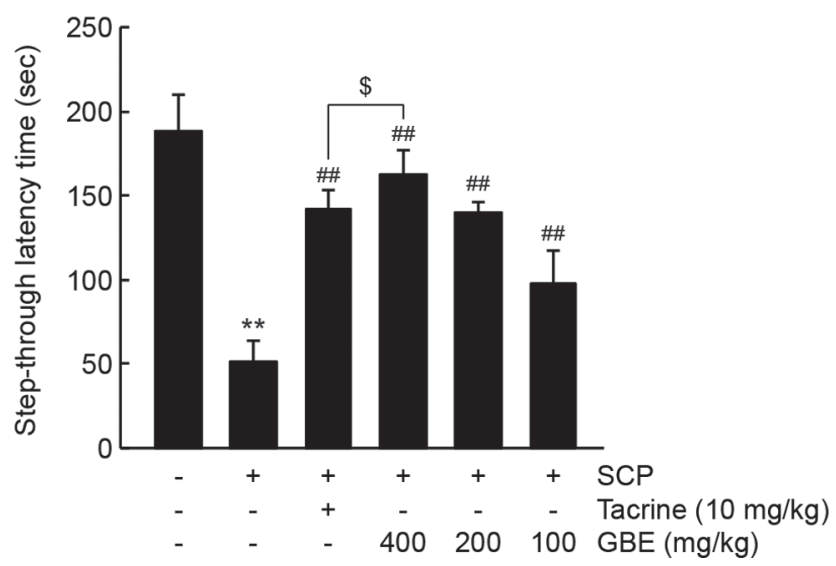

D

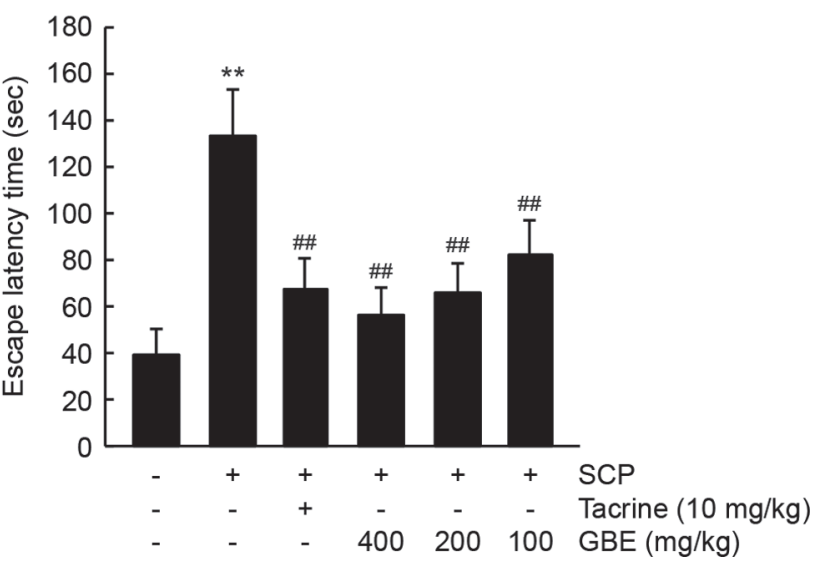

Figure 2. GBE prevents SCP-induced memory impairment in mice. (A) In vivo experimental designs for drug treatment, behavior testing, and biochemical analysis; $100-400 \mathrm{mg} / \mathrm{kg}$ of GBE or $10 \mathrm{mg} / \mathrm{kg}$ of tacrine was orally administered once per day for 4 weeks, and SCP was injected three times $1 \mathrm{~h}$ after GBE/tacrine administration on days 6, 13 and 27. (B) Mouse BW. All mice were fasted for $12 \mathrm{~h}$ before the first GBE/tacrine administration. BW (n=20/group) was measured on days $-1,0,1,13,20,27$ and 28 after the initial drug administration. (C) Passive avoidance test. The time from the light/noise compartment to the electric grid floor for each individual mouse was considered a measure of step-through latency time (n=10/group). (D) Morris water maze test. The time from the water to the submerged platform for each individual mouse considered a measure of escape latency time (n=10/group). All values are expressed as the mean \pm SD. ${ }^{* *} \mathrm{P}<0.01$ vs. vehicle-treated group; ${ }^{\# \#} \mathrm{P}<0.01$ vs. SCP-injected group; ${ }^{\$} \mathrm{P}<0.05$ vs. tacrine-treated group). BW, body weight; GBE, ginseng berry aqueous extract; SCP, scopolamine; SD, standard deviation.

changed BDNF, Akt, and ERK1 mRNA levels compared with the SCP-injected group (Akt: $\mathrm{P}<0.05$; BDNF and ERK1: $\mathrm{P}<0.01)$. Moreover, the mRNA levels of PI3K, Akt, and ERK2 in the $400 \mathrm{mg} / \mathrm{kg}$ GBE group were significantly higher than those in the tacrine group (PI3K: $\mathrm{P}<0.05$; Akt and ERK2: $\mathrm{P}<0.01$; Table I).

GBE increases antioxidant activity in the cerebral cortex. To investigate whether GBE increases antioxidant capacity in vivo, we first measured the level of malondialdehyde (a marker of lipid peroxidation) in the cerebral cortex. SCP injection significantly increased the level of malondialdehyde $(\mathrm{P}<0.01)$, showing that SCP promoted lipid peroxidation in the brain. By contrast, administration of all three doses of GBE or tacrine significantly reduced lipid peroxidation $(\mathrm{P}<0.01)$. The decrease in lipid peroxidation after treatment with the three doses of GBE was comparable to that by tacrine (Fig. 4A). In addition, SCP decreased GSH levels and CAT and SOD activities in the cerebral cortex $(\mathrm{P}<0.01)$, and administration of $\mathrm{GBE}$ or tacrine significantly prevented the decreases in GSH levels and CAT and SOD activity (CAT activity in tacrine: $\mathrm{P}<0.05$; $\mathrm{P}<0.01$ for the others). In contrast, the decrease in CAT activity was not prevented in the group following administration with $100 \mathrm{mg} / \mathrm{kg}$ of GBE. GSH and SOD activity levels in mice treated with $400 \mathrm{mg} / \mathrm{kg}$ of GBE were higher than those in mice treated with tacrine $(\mathrm{P}<0.05$; Fig. 4B-D).

\section{Discussion}

It has been reported that ginseng root, its enriched fractions, and isolated bioactive compounds can attenuate SCP-induced memory impairment in experimental animals (16,18,25-30). Protection of the cholinergic nervous system via antioxidant and anti-inflammatory actions is associated with the pharmacological effect of ginseng root in animals with SCP-induced amnesia $(16,25,26,28)$. However, the effects of ginseng berries on memory impairment remain poorly understood. Although similar beneficial effects to those of ginseng root have been reported in other parts of the $P$. ginseng plant $(6,8,9)$, certain bioactive compounds are selectively distributed throughout 
Table I. The effect of GBE administration on mRNA levels related to memory in SCP-induced memory-impaired mice.

\begin{tabular}{lccccccc}
\hline Group & BDNF & PI3K & Akt & ERK1 & ERK2 & CaMK IV & CREB \\
\hline Vehicle & $1.01 \pm 0.13$ & $1.01 \pm 0.10$ & $1.00 \pm 0.11$ & $0.99 \pm 0.07$ & $1.02 \pm 0.09$ & $1.01 \pm 0.14$ & $0.99 \pm 0.12$ \\
SCP & $0.37 \pm 0.10^{\mathrm{a}}$ & $0.30 \pm 0.11^{\mathrm{a}}$ & $0.38 \pm 0.08^{\mathrm{a}}$ & $0.30 \pm 0.09^{\mathrm{a}}$ & $0.28 \pm 0.09^{\mathrm{a}}$ & $0.31 \pm 0.12^{\mathrm{a}}$ & $0.33 \pm 0.09^{\mathrm{a}}$ \\
+ Tacrine $10 \mathrm{mg} / \mathrm{kg}$ & $0.63 \pm 0.13^{\mathrm{b}}$ & $0.46 \pm 0.10^{\mathrm{c}}$ & $0.60 \pm 0.10^{\mathrm{b}}$ & $0.53 \pm 0.06^{\mathrm{b}}$ & $0.53 \pm 0.10^{\mathrm{b}}$ & $0.51 \pm 0.08^{\mathrm{b}}$ & $0.55 \pm 0.13^{\mathrm{b}}$ \\
+ GBE $400 \mathrm{mg} / \mathrm{kg}$ & $0.75 \pm 0.11^{\mathrm{b}}$ & $0.67 \pm 0.14^{\mathrm{b}} \mathrm{e}$ & $0.80 \pm 0.12^{\mathrm{b}, \mathrm{d}}$ & $0.71 \pm 0.15^{\mathrm{b}}$ & $0.72 \pm 0.12^{\mathrm{b}, \mathrm{d}}$ & $0.62 \pm 0.13^{\mathrm{b}}$ & $0.69 \pm 0.14^{\mathrm{b}}$ \\
+ GBE $200 \mathrm{mg} / \mathrm{kg}$ & $0.65 \pm 0.11^{\mathrm{b}}$ & $0.47 \pm 0.13^{\mathrm{c}}$ & $0.60 \pm 0.13^{\mathrm{b}}$ & $0.54 \pm 0.07^{\mathrm{b}}$ & $0.52 \pm 0.10^{\mathrm{b}}$ & $0.50 \pm 0.07^{\mathrm{b}}$ & $0.54 \pm 0.09^{\mathrm{b}}$ \\
+ GBE $100 \mathrm{mg} / \mathrm{kg}$ & $0.56 \pm 0.08^{\mathrm{b}}$ & $0.42 \pm 0.08$ & $0.55 \pm 0.11^{\mathrm{c}}$ & $0.48 \pm 0.07^{\mathrm{b}}$ & $0.39 \pm 0.08$ & $0.44 \pm 0.05$ & $0.46 \pm 0.10$ \\
\hline
\end{tabular}

All values are expressed as the mean $\pm \mathrm{SD}$ of 10 mice. ${ }^{\mathrm{a}} \mathrm{P}<0.01$ vs. vehicle-treated group; ${ }^{\mathrm{b}} \mathrm{P}<0.01,{ }^{\mathrm{c}} \mathrm{P}<0.05 \mathrm{vs}$. $\mathrm{SCP}$-injected group; ${ }^{\mathrm{d}} \mathrm{P}<0.01$, ${ }^{e} \mathrm{P}<0.05$ vs. tacrine-treated group. BDNF, brain-derived neurotrophic factor; $\mathrm{CaMK}, \mathrm{Ca}^{2+} / \mathrm{calmodulin}^{-d e p e n d e n t ~ p r o t e i n ~ k i n a s e ; ~} \mathrm{CREB}$, cAMP response element binding protein; ERK, extracellular-regulated protein kinase; GBE, ginseng berry aqueous extract; PI3K, phosphoinositide 3-kinase; SCP, scopolamine; SD, standard deviation.
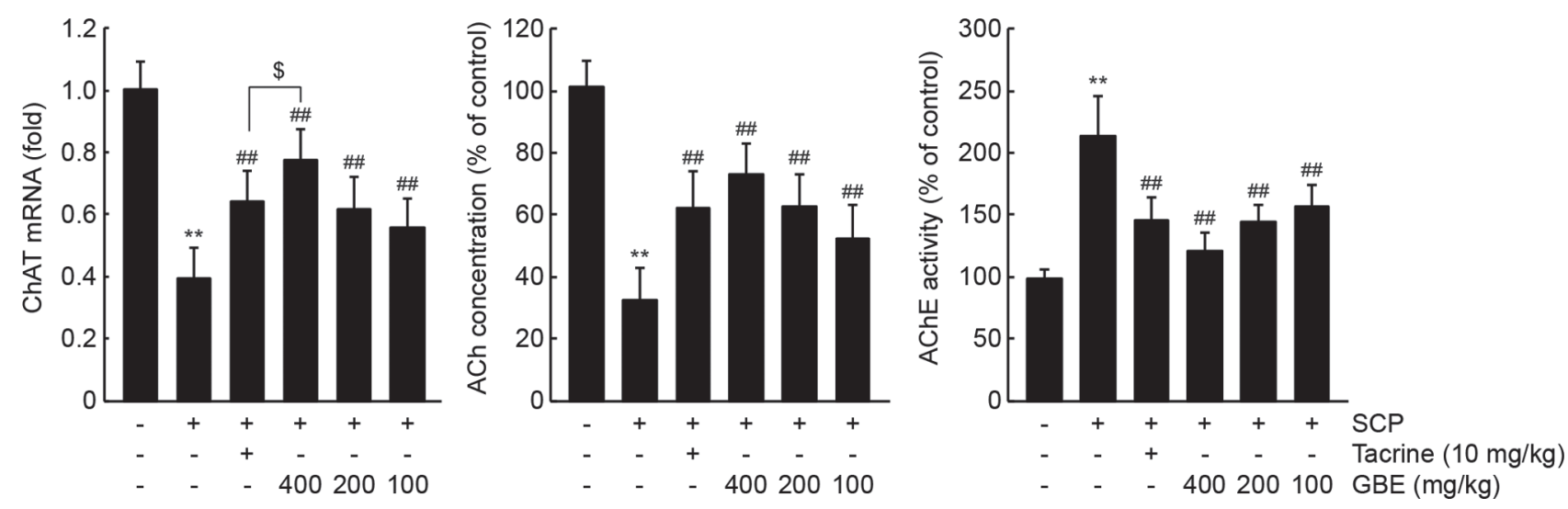

Figure 3. GBE enhances cholinergic nervous system activity in the hippocampus of SCP-injected mice. ChAT mRNA levels (left), ACh concentrations (middle), and AChE activities (right) in the hippocampus were determined from mice that underwent the passive avoidance test. All values are expressed as the mean \pm SD of 10 mice. ${ }^{* *} \mathrm{P}<0.01$ vs. vehicle-treated group; ${ }^{\# \#} \mathrm{P}<0.01$ vs. SCP-injected group; ${ }^{\$} \mathrm{P}<0.05$ vs. tacrine-treated group. ACh, acetylcholine; AChE, acethylcholinesterase; ChAT, choline acetyltransferase; GBE, ginseng berry aqueous extract; SCP, scopolamine; SD, standard deviation.

$P$. ginseng (21). Before investigating the anti-amnesic effect of GBE, we performed an HPLC analysis to assess the quality of GBE and found that GBE used in the present study contained $29.13 \pm 0.15 \mathrm{mg} / \mathrm{g}$ of ginsenoside Re.

Lee et al (2017) reported that 29 of the 58 ginsenosides previously tested are found in ginseng berry methanolic extract (21). Ginsenosides F1 and Rg4 are found only in the berry at low concentrations, while ginsenoside $\mathrm{Re}, \mathrm{Rg} 2, \mathrm{~F} 4$, $\mathrm{Rg} 5$, malonylated $\mathrm{Rd}$, malonylated Rb2, malonylated Rc, and malonylated $\mathrm{Rb} 1$ are concentrated in berry compared to other parts of the ginseng plant (21). Moreover, previous results from different groups have shown that ginsenoside $\mathrm{Re}, \mathrm{Rf}, \mathrm{Rb} 1, \mathrm{Rc}, \mathrm{Rb} 2$, and $\mathrm{Rd}$ are contained in ginseng berry aqueous extract (12), which is the identical to the extract used in this study. Ginsenoside Re is found to be the most abundant ginsenoside in ginseng berry $(12,21)$. Although there is no direct evidence that ginsenoside Re ameliorates SCP-induced amnesia, an accumulation of evidence suggests that ginsenoside Re enhances cognitive function through the reduction of amyloid $\beta(31,32)$. Additionally, other ginsenosides found in GBE have been reported to exhibit neuroprotective activities (33-35). Therefore, ginsenoside Re and other unidentified compounds in GBE are thought to contribute cooperatively to mitigating cognitive deficits caused by SCP. Further studies are needed to identify the major compounds involved in GBE-mediated neuroprotection.

In the present study, $\mathrm{SCP}(1 \mathrm{mg} / \mathrm{kg})$ was intraperitoneally injected three times in mice to induce memory loss. SCP is a nonselective antagonist of the muscarinic $\mathrm{ACh}$ receptor, which reduces cholinergic transmission in the central nervous system and causes cognitive dysfunction, including long-term memory loss (36). Therefore, SCP is one of the most extensively used neurotoxins to elucidate possible therapeutic agents for modulating memory impairment $(16,18,26-30)$. To study the neuroprotective effects of GBE related to memory, we conducted two behavioral tests after SCP injection. The passive avoidance test has been performed to investigate non-spatial long-term memory after an aversive experience (37). In parallel with previous reports $(16,18,26,29)$, SCP significantly decreased the step-through latency time. However, GBE administration significantly prolonged the step-through latency time in a dose-dependent manner. The Morris water maze test is another behavioral test used to assess long-term and spatial memory in the hippocampus $(19,38)$. In the present study, SCP injection significantly increased the latency time to the escape platform in the water maze, whereas GBE mitigated 

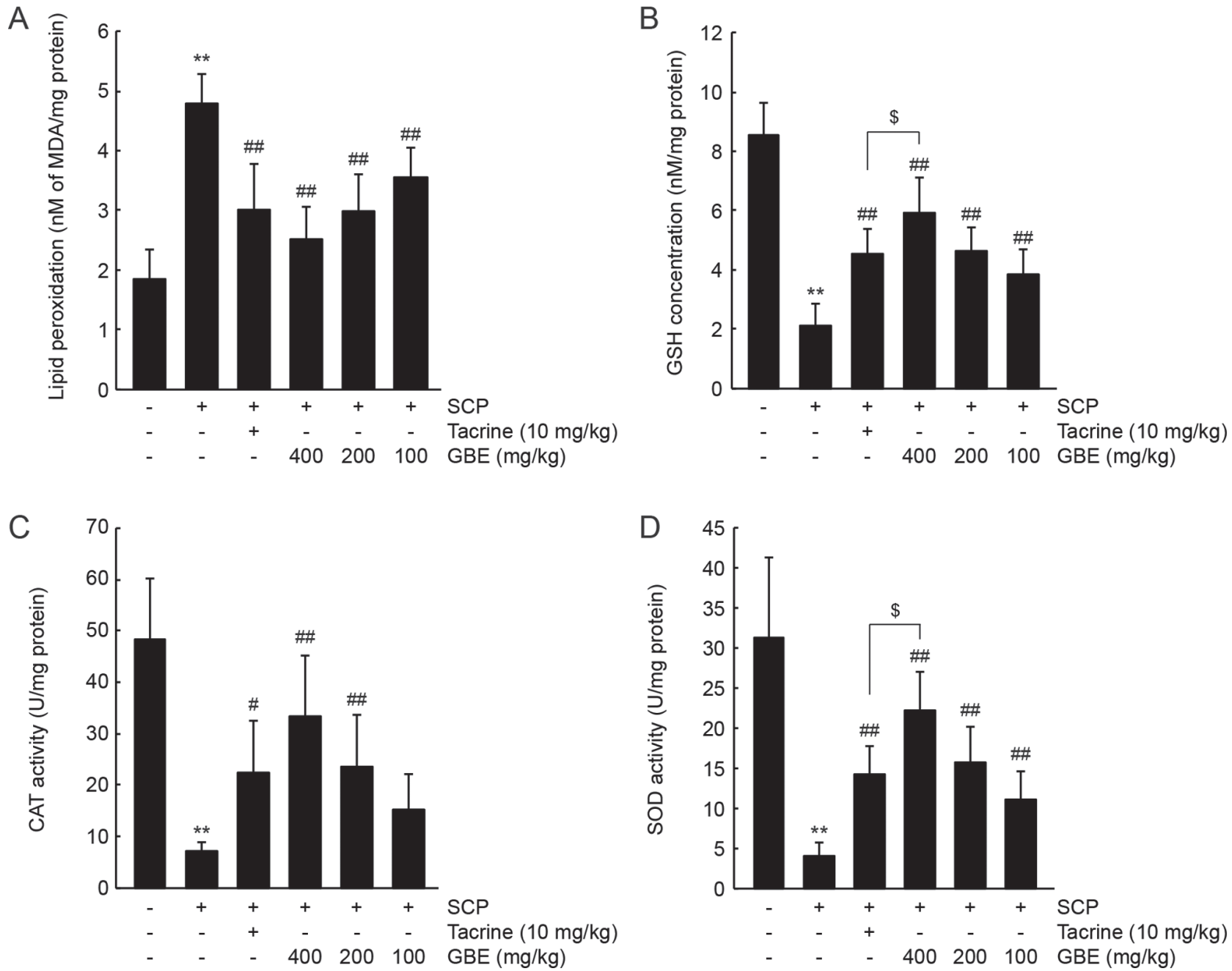

Figure 4. GBE increases antioxidant activity in the SCP-injected mice. (A) Lipid peroxidation, (B) GSH concentration, and (C) CAT and (D) SOD activities in the cerebral cortex were determined from mice that had performed the Morris water maze test. All values are expressed as the mean $\pm \mathrm{SD}$ of 10 mice. ${ }^{* *} \mathrm{P}<0.01$ vs. vehicle-treated group; ${ }^{\# \#} \mathrm{P}<0.01,{ }^{\prime \prime} \mathrm{P}<0.05$ vs. SCP-injected group; ${ }^{~} \mathrm{P}<0.05$ vs. tacrine-treated group. $\mathrm{CAT}$, catalase; GBE, ginseng berry aqueous extract; GSH, glutathione; MDA, malondialdehyde; SCP, scopolamine; SD, standard deviation; SOD, superoxide dismutase.

the SCP-induced spatial memory impairment as shown by a decreased escape time.

ACh, which is synthesized by ChAT, is a critical neurotransmitter for regulating cognitive function. In addition, memory loss by SCP is closely correlated with an increase in AChE (an ACh-hydrolyzing enzyme in the cholinergic synaptic cleft) activity and a subsequent reduction in $\mathrm{ACh}$ in the hippocampus $(26,27)$. To confirm whether GBE restores long-term memory via the cholinergic nervous system, we further measured hippocampal levels of ACh and its metabolizing enzymes. SCP increased AChE activity and decreased $\mathrm{ACh}$ and ChAT mRNA levels in the hippocampus, which was consistent with previous reports $(26,27)$. However, GBE administration significantly reduced these changes. Therefore, these results suggest that GBE attenuates SCP-induced memory deficit by enhancing cholinergic signaling in the hippocampus.

BDNF is a neurotrophic factor that contributes to neuronal plasticity and synaptic transmission (23). BDNF enhances memory function by promoting the formation of long-term potentiation and by up-regulating the sensitivity of $\mathrm{N}$-methyl-D-aspartate receptors in the hippocampus $(22,39,40)$. Binding of BDNF to tropomyosin receptor kinase B (TrkB) facilitates dimerization and phosphorylation of TrkB tyrosine residues, and recruits diverse Src homology 2 adaptor molecules, including phospholipase $\mathrm{C}$, insulin receptor substrate, and Shc $(23,41)$. Phospholipase $\mathrm{C}$ activates $\mathrm{Ca}^{2+}$-dependent calmodulin kinase by increasing intracellular $\mathrm{Ca}^{2+}$ levels. In addition, insulin receptor substrate and Shc activate the phosphoinositide 3-kinase-dependent Akt and Ras/Raf/MEK-dependent ERK signaling pathways (23). Specifically, the BDNF signaling cascades regulate $\mathrm{CREB}$, which is an essential transcription factor necessary for late-stage of long-term potentiation and long-term memory formation in the hippocampus $(42,43)$. The present results demonstrated that SCP significantly decreased BDNF mRNA levels and its related signaling molecules, and the administration of GBE prevented these reductions in the hippocampus. Although GBE may restore long-term memory by upregulating the expression of BDNF-related signaling molecules in the hippocampus, further studies on the covalent modifications (e.g., phosphorylation) of signaling molecules are needed to establish the role of the GBE in signaling pathway related to memory.

We also showed that GBE protected HT-22 cells from glutamate- and $\mathrm{H}_{2} \mathrm{O}_{2}$-induced cytotoxicity. Because of its 
low endogenous antioxidant capacity, an abundance of polyunsaturated fatty acids, and high oxygen consumption rate, the brain is one of the most susceptible organs to oxidative stress $(44,45)$. Therefore, oxidative stress is important in the progression of neurodegenerative diseases, including AD (44). It has been reported that ginseng protects the brain from oxidative stress via activation of nuclear factor-E2 related factor 2 (Nrf2) $(16,25,46)$. Moreover, genetic deletion of Nrf2 abolishes the protective effect of compound $\mathrm{K}$ (a major aglycosylated metabolite of protopanaxadiol-type ginsenosides) against SCP-induced amnesia (16). In the resting state, Nrf2 resides in the cytoplasm by binding to Kelch-like $\mathrm{ECH}$-associated protein 1 and is autonomously degraded by the ubiquitin-dependent proteasome system. Antioxidants as well as oxidative stress disturb protein-protein interaction between $\mathrm{Nrf} 2$ and Kelch-like ECH-associated protein 1, and translocate Nrf2 into the nucleus. Nuclear Nrf2 heterodimerizes with Jun or small Maf and subsequently binds to the antioxidant response elements of many antioxidant genes, including $\gamma$-glutamate cysteine ligase (a rate-limiting enzyme of GSH synthesis), CAT, or SOD (47). In this study, SCP injection increased lipid peroxidation, decreased GSH levels, and reduced CAT and SOD activity, which is in agreement with previous observations that SCP provokes oxidative stress in the brain $(26,48)$. GBE administration inhibited lipid peroxidation significantly and elevated the levels of GSH while also elevating CAT and SOD activities in a concentration-dependent manner. Therefore, these results suggest that GBE may attenuate SCP-induced memory impairment, potentially by protecting neurons from oxidative stress. However, further studies investigating the detailed cellular mechanisms involved, including Nrf2 activation, are warranted.

In this study, we compared the pharmacological effect of GBE with tacrine. Although some statistical results (e.g., step-through latency time, GSH level, SOD activity, and ChAT, PI-3K, Akt, and ERK2 mRNA levels) showed that GBE $(400 \mathrm{mg} / \mathrm{kg}$ ) was more potent than tacrine, most of the anti-amnesic effects of GBE (200-400 mg/kg) were comparable to those of tacrine $(10 \mathrm{mg} / \mathrm{kg})$. In conclusion, the results of this study suggest that GBE alleviates SCP-induced memory impairment by restoring the cholinergic nervous system, mRNA expression of BDNF-related signaling molecules, and antioxidant capacity. Therefore, ginseng berry may be a promising complementary medicine for managing various neurodegenerative disorders with memory impairment.

\section{Acknowledgments}

Not applicable.

\section{Funding}

The current study was supported by the National Research Foundation of Korea (NRF) funded by Korean government (MSIP) (grant no. 2018R1A5A2025272).

\section{Availability of data and materials}

The datasets used and/or analyzed during the current study are available from the corresponding author on reasonable request.

\section{Authors' contributions}

SKK designed the study. JRH, YSC, JKK and SKK conducted the research. JRH, IJC and SKK analyzed the data. JRH, IJC and SKK co-wrote the manuscript. IJC and SKK had primary responsibility for the final content. All authors approved the final draft of the manuscript.

\section{Ethics approval and consent to participate}

Animal experiments were conducted according to the national regulations regarding the use and welfare of laboratory animals and were approved by the Institutional Animal Care and Use Committee in Daegu Haany University (approval no. DHU2017-081).

\section{Patient consent for publication}

Not applicable.

\section{Competing interests}

The authors declare that they have no competing of interests.

\section{References}

1. Burns A and Iliffe S: Alzheimer's disease. BMJ 338: b158, 2009.

2. Golde TE: Disease modifying therapy for AD? J Neurochem 99: 689-707, 2006.

3. Francis PT, Palmer AM, Snape M and Wilcock GK: The cholinergic hypothesis of Alzheimer's disease: A review of progress. J Neurol Neurosurg Psychiatry 66: 137-147, 1999.

4. Ibach B and Haen E: Acetylcholinesterase inhibition in Alzheimer's Disease. Curr Pharm Des 10: 231-251, 2004.

5. Rountree SD, Chan W, Pavlik VN, Darby EJ, Siddiqui S and Doody RS: Persistent treatment with cholinesterase inhibitors and/or memantine slows clinical progression of Alzheimer disease. Alzheimers Res Ther 1: 7, 2009.

6. Kim CK, Cho DH, Lee KS, Lee DK, Park CW, Kim WG, Lee SJ, Ha KS, Goo Taeg O, Kwon YG and Kim YM: Ginseng berry extract prevents atherogenesis via anti-inflammatory action by upregulating phase II gene expression. Evid Based Complement Alternat Med 2012: 490301, 2012.

7. Kim YK, Yoo DS, Xu H, Park NI, Kim HH, Choi JE and Park SU: Ginsenoside content of berries and roots of three typical Korean ginseng (Panax ginseng) cultivars. Nat Prod Commun 4: 903-906, 2009.

8. In-Ho C, Byung-Woo K, Yun-Jae P, Han-Joo L, Sok P and Namju L: Ginseng berry extract increases nitric oxide level in vascular endothelial cells and improves cGMP expression and blood circulation in muscle cells. J Exerc Nutrition Biochem 22: 6-13, 2018.

9. Dey L, Xie JT, Wang A, Wu J, Maleckar SA and Yuan CS: Anti-hyperglycemic effects of ginseng: Comparison between root and berry. Phytomedicine 10: 600-605, 2003.

10. Seo E, Kim S, Lee SJ, Oh BC and Jun HS: Ginseng berry extract supplementation improves age-related decline of insulin signaling in mice. Nutrients 7: 3038-3053, 2015.

11. Yang SO, Park HR, Sohn ES, Lee SW, Kim HD, Kim YC, Kim KH, Na SW, Choi HK, Arasu MV and Kim YO: Classification of ginseng berry (Panax ginseng C.A. MEYER) extract using $1 \mathrm{H}$ NMR spectroscopy and its inhibition of lipid accumulation in 3T3-L1 cells. BMC Complement Altern Med 14: 455, 2014.

12. Kim MH, Lee J, Jung S, Kim JW, Shin JH and Lee HJ: The involvement of ginseng berry extract in blood flow via regulation of blood coagulation in rats fed a high-fat diet. J Ginseng Res 41: 120-126, 2017.

13. Ma ZN, Liu Z, Wang Z, Ren S, Tang S, Wang YP, Xiao SY, Chen $\mathrm{C}$ and Li W: Supplementation of American ginseng berry extract mitigated cisplatin-evoked nephrotoxicity by suppressing ROS-mediated activation of MAPK and NF- $\kappa$ B signaling pathways. Food Chem Toxicol 110: 62-73, 2017. 
14. Xu XY, Wang Z, Ren S, Leng J, Hu JN, Liu Z, Chen C and Li W: Improved protective effects of American ginseng berry against acetaminophen-induced liver toxicity through TNF- $\alpha$-mediated caspase-3/-8/-9 signaling pathways. Phytomedicine 51: 128-138, 2018.

15. Zhang W, Xu L, Cho SY, Min KJ, Oda T, Zhang L, Yu Q and Jin JO: Ginseng berry extract attenuates dextran sodium sulfate-induced acute and chronic colitis. Nutrients 8: 199, 2016

16. Seo JY, Ju SH, Oh J, Lee SK and Kim JS: Neuroprotective and cognition-enhancing effects of compound $\mathrm{K}$ isolated from red ginseng. J Agric Food Chem 64: 2855-2864, 2016.

17. Maurice T, Lockhart BP and Privat A: Amnesia induced in mice by centrally administered beta-amyloid peptides involves cholinergic dysfunction. Brain Res 706: 181-193, 1996.

18. Kim J, Kim SH, Lee DS, Lee DJ, Kim SH, Chung S and Yang HO: Effects of fermented ginseng on memory impairment and $\beta$-amyloid reduction in Alzheimer's disease experimenta models. J Ginseng Res 37: 100-107, 2013.

19. Morris R: Development of a water maze procedure for studying spatial learning in the rat. J Neurosci Methods 11: 47-60, 1984.

20. Livak KJ and Schmittgen TD: Analysis of relative gene expression data using real-time quantitative PCR and the 2(-Delta Delta C(T)) method. Methods 25: 402-408, 2001.

21. Lee JW, Choi BR, Kim YC, Choi DJ, Lee YS, Kim GS, Baek NI, Kim SY and Lee DY: Comprehensive profiling and quantification of ginsenosides in the root, stem, leaf, and berry of Panax ginseng by UPLC-QTOF/MS. Molecules 22: E2147, 2017.

22. Nakajo Y, Miyamoto S, Nakano Y, Xue JH, Hori T and Yanamoto H: Genetic increase in brain-derived neurotrophic factor levels enhances learning and memory. Brain Res 1241: 103-109, 2008.

23. Cunha C, Brambilla R and Thomas KL: A simple role for BDNF in learning and memory? Front Mol Neurosci 3: 1, 2010.

24. Martin SJ, Grimwood PD and Morris RG: Synaptic plasticity and memory: An evaluation of the hypothesis. Annu Rev Neurosci 23: 649-711, 2000.

25. Yang Q, Lin J, Zhang H, Liu Y, Kan M, Xiu Z, Chen X, Lan X, Li X, Shi $X$, et al: Ginsenoside compound $\mathrm{K}$ regulates amyloid $\beta$ via the Nrf2/Keap1 signaling pathway in mice with scopolamine hydrobromide-induced memory impairments. J Mol Neurosci 67 62-71, 2019.

26. Lu C, Lv J, Dong L, Jiang N, Wang Y, Wang Q, Li Y, Chen S, Fan B, Wang F and Liu X: Neuroprotective effects of 20(S)-protopanaxatriol (PPT) on scopolamine-induced cognitive deficits in mice. Phytother Res 32: 1056-1063, 2018.

27. Kim J, Shim J, Lee S, Cho WH, Hong E, Lee JH, Han JS, Lee HJ and Lee KW: Rg3-enriched ginseng extract ameliorates scopolamine-induced learning deficits in mice. BMC Complement Altern Med 16: 66, 2016

28. Xu T, Shen X, Yu H, Sun L, Lin W and Zhang C: Water-soluble ginseng oligosaccharides protect against scopolamine-induced cognitive impairment by functioning as an antineuroinflammatory agent. J Ginseng Res 40: 211-219, 2016.

29. Peña ID, Yoon SY, Kim HJ, Park S, Hong EY, Ryu JH, Park IH and Cheong JH: Effects of ginseol k-g3, an Rg3-enriched fraction, on scopolamine-induced memory impairment and learning deficit in mice. J Ginseng Res 38: 1-7, 2014.

30. Jin SH, Park JK, Nam KY, Park SN and Jung NP: Korean red ginseng saponins with low ratios of protopanaxadiol and protopanaxatriol saponin improve scopolamine-induced learning disability and spatial working memory in mice. J Ethnopharmacol 66: 123-129, 1999.

31. Li J, Liu Y, Li W, Wang Z, Guo P, Li L and Li N: Metabolic profiling of the effects of ginsenoside Re in an Alzheimer's disease mouse model. Behav Brain Res 337: 160-172, 2018.

32. Chen F, Eckman EA and Eckman CB: Reductions in levels of the Alzheimer's amyloid beta peptide after oral administration of ginsenosides. FASEB J 20: 1269-1271, 2006.
33. Du Y, Fu M, Wang YT and Dong Z: Neuroprotective effects of ginsenoside $\mathrm{Rf}$ on amyloid- $\beta$-induced neurotoxicity in vitro and in vivo. J Alzheimers Dis 64: 309-322, 2018.

34. Liu JF, Yan XD, Qi LS, Li L, Hu GY, Li P and Zhao G: Ginsenoside Rd attenuates $A \beta 25$-35-induced oxidative stress and apoptosis in primary cultured hippocampal neurons. Chem Bio Interact 239: 12-18, 2015.

35. Wang Q, Sun LH, Jia W, Liu XM, Dang HX, Mai WL, Wang N, Steinmetz A, Wang YQ and Xu CJ: Comparison of ginsenosides $\mathrm{Rg} 1$ and $\mathrm{Rb} 1$ for their effects on improving scopolamine-induced learning and memory impairment in mice. Phytother Res 24: $1748-1754,2010$

36. Klinkenberg I and Blokland A: The validity of scopolamine as a pharmacological model for cognitive impairment: A review of animal behavioral studies. Neurosci Biobehav Rev 34 1307-1350, 2010

37. Lorenzini CA, Baldi E, Bucherelli C, Sacchetti B and Tassoni G: Role of dorsal hippocampus in acquisition, consolidation and retrieval of rat's passive avoidance response: A tetrodotoxin functional inactivation study. Brain Res 730: 32-39, 1996.

38. Barnes CA, Danysz W and Parsons CG: Effects of the uncompetitive NMDA receptor antagonist memantine on hippocampal long-term potentiation, short-term exploratory modulation and spatial memory in awake, freely moving rats. Eur J Neurosci 8: 565-571, 1996

39. Madara JC and Levine ES: Presynaptic and postsynaptic NMDA receptors mediate distinct effects of brain-derived neurotrophic factor on synaptic transmission. J Neurophysiol 100: 3175-3184, 2008.

40. Korte M, Carroll P, Wolf E, Brem G, Thoenen H and Bonhoeffer T: Hippocampal long-term potentiation is impaired in mice lacking brain-derived neurotrophic factor. Proc Natl Acad Sci USA 92: 8856-8860, 1995.

41. Segal RA: Selectivity in neurotrophin signaling: Theme and variations. Annu Rev Neurosci 26: 299-310, 2003.

42. Bozon B, Kelly A, Josselyn SA, Silva AJ, Davis S and Laroche S: MAPK, CREB and zif268 are all required for the consolidation of recognition memory. Philos Trans R Soc Lond B Biol Sci 358: 805-814, 2003

43. Korte M, Kang H, Bonhoeffer T and Schuman E: A role of BDNF in the late-phase of hippocampal long-term potentiation. Neuropharmacology 37: 553-559, 1998.

44. Singh A, Kukreti R, Saso L and Kukreti S: Oxidative stress: A key modulator in neurodegenerative diseases. Molecules 24: E1583, 2019.

45. Olanow CW: An introduction to the free radical hypothesis in Parkinson's disease. Ann Neurol 32 (Suppl): S2-S9, 1992.

46. Liu L, Vollmer MK, Ahmad AS, Fernandez VM, Kim H and Doré S: Pretreatment with Korean red ginseng or dimethyl fumarate attenuates reactive gliosis and confers sustained neuroprotection against cerebral hypoxic-ischemic damage by an Nrf2-dependent mechanism. Free Radic Biol Med 131: 98-114, 2019.

47. Sivandzade F, Prasad S, Bhalerao A and Cucullo L: NRF2 and $\mathrm{NF}-\kappa \mathrm{B}$ interplay in cerebrovascular and neurodegenerative disorders: Molecular mechanisms and possible therapeutic approaches. Redox Biol 21: 101059, 2019.

48. Lee MR, Yun BS, Park SY, Ly SY, Kim SN, Han BH and Sung CK: Anti-amnesic effect of Chong-Myung-Tang on scopolamine-induced memory impairments in mice. J Ethnopharmacol 132: 70-74, 2010.

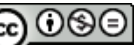

This work is licensed under a Creative Commons Attribution-NonCommercial-NoDerivatives 4.0 International (CC BY-NC-ND 4.0) License. 